\title{
CARTOGRAFIA, INFORMAÇÃO GEOGRÁFICA E NOVAS TECNOLOGIAS ${ }^{1}$
}

Aziz Serradj ${ }^{2}$

Resumo: A presente comunicação trata da evolução da utilização da informação geográfica e sua cartografia após três revoluções tecnológicas: a digital, a multimídia e a da comunicação. Após breve apresentação da informação geográfica, veremos quais são as grandes transformações ocorridas na Cartografia. A primeira grande revolução é digital, que forneceu um poder de cálculo muito importante, permitindo não apenas realizar mapas com a ajuda de computadores, um ganho de rapidez de execução e precisão de traço, mas também de modelização dos dados temáticos para obter mapas deformados (TCP), exprimindo funcionalidades como a acessibilidade ou outras. A segunda revolução é multimídia, que não apenas tocou profundamente a Cartografia ao oferecer novas ferramentas à disciplina, mas se inscreve no contexto cultural e social atual. A multimídia propõe ao público imagens, no largo senso do termo, animadas, sonoras... aquilo que as tornam mais atrativas e intuitivas, permitindo uma melhor compreensão dos fenômenos tratados. As animações temporais e processuais colocam em evidência as mudanças no tempo e facilitam as simulações. Estas últimas se apoiam sob uma modelização da informação geográfica com a ajuda, por exemplo, dos autômatos celulares ou de sistemas multi-agentes, que permitem levar em conta eventuais auto-organizações espaciais e que se constituem de uma ferramenta apreciável no quadro de um sistema de ajuda à decisão. A multimídia pode inserir outro sentido além da visão: a audição. Como há uma relação direta entre o que vemos e o que entendemos, a utilização do som permite memorizar melhor $o$ conteúdo de um mapa. Enfim, a comunicação via Internet e a "Web Cartografia" permitem a difusão de mapas completos ou bem realizados com interativid-ade pelo usuário, à distância, e recuperados para serem utilizados imediatamente. A Cartografia se torna onipresente e universal!

Palavras-chave: cartografia, informação geográfica, novas tecnologias, cartografia transformacional, simulação, cartografia com internet.

From the analogical cartography to the neocartography: will our maps ever be the same?

Abstract: La présente communication porte sur l'évolution de l'utilisation de l'information géographique et sa cartographie après les trois révolutions technologiques : le numérique, le multimédia et la communication. Après une brève présentation de l'information géographique, nous verrons quelles sont les grandes transformations survenues dans sa cartographie. Le premier grand chamboulement vient du numérique qui a fourni une puissance de calcul toujours plus importante, permettant non seulement de réaliser des cartes à l'aide des ordinateurs en gagnant en rapidité d'exécution et précision de tracé, mais aussi de modéliser les données thématiques pour obtenir des cartes déformées (TCP) exprimant des fonctionnalités comme l'accessibilité ou autre. Le second bouleversement vient du multimédia ; ce dernier non seulement a touché en profondeur la cartographie en

\footnotetext{
${ }^{1}$ Esta comunicação é inspirada nas obras de cartografia temática publicadas entre 2007 e 2008 por C. Cauvin, F. Escobar e A. Serradj e certos trabalhos dos membros do Laboratório Imagem, Cidade e Meio Ambiente (LIVE), da Faculdade de Geografia da Universidade de Estrasburgo (UdS). Original em francês. Tradução para o português de Ludmila Girardi, em janeiro de 2014.

${ }^{2}$ Université de Strasbourg, Faculté de Géographie Laboratoire Image, Ville, Environnement (ERL-7030 du CNRS). 3 rue de l'Argonne, 67000 Strasbourg-France E-mail: aziz.serradj@live-cnrs.unistra.fr DOI: 10.7154/RDG.2014.0114.0020
} 
offrant de nouveaux outils à cette discipline, mais s'inscrit aussi dans le contexte culturel et sociétal actuel. Le multimédia propose au public des images, au sens large du terme, animées, sonores... ce qui les rend plus attractives et intuitives permettant ainsi, une meilleure compréhension des phénomènes traités. Les animations temporelles et processuelles mettent en évidence les changements dans le temps et facilitent les simulations. Ces dernières qui s'appuient sur une modélisation de l'information géographique, à l'aide, par exemple, des automates cellulaires ou des systèmes multi-agents, permettent de rendre compte d'éventuelles auto-organisations spatiales et constituent un outil appréciable dans le cadre d'un système d'aide à la décision. Le multimédia peut mettre en jeu un autre sens que la vue : le son. Comme il y a une relation directe entre ce que l'on voit et ce que l'on entend, l'utilisation du son permet de mieux mémoriser le contenu de la carte. Enfin, la communication par le biais de l'Internet et de la Web Cartographie permet de diffuser des cartes toutes faites ou bien réalisées en interactivité par l'utilisateur, à distance, et récupérées pour être utilisées immédiatement. La cartographie devient omniprésente et universelle!

Mots-Clés: cartographie, information géographique, nouvelles technologies, cartographie transformationnelle, simulation, cartographie avec internet.

\section{INTRODUÇÃO}

Nesta comunicação, que se inscreve na temática da Mesa Redonda 4 intitulada "Tecnologia da Informação Geográfica", após lembrar num primeiro momento o que é a Informação Geográfica, num segundo momento mostramos como a evolução tecnológica (Digital, Multimídia e Comunicação) pôde mudar suas abordagens de tratamento e de representação.

A informação geográfica é o conhecimento dos fenômenos geográficos, com uma descrição tão fiel e completa quanto possível. Tratam-se de informações descritoras de objetos, fenômenos, seres vivos ou sociedades desde que sejam ligadas a um território. O cartógrafo vai gerar uma modelização espacial acessível ao usuário e compreensível graças à legenda. Assim, o mapa obtido é o produto de interpretação do cartógrafo: "a informação geográfica transmitida ao cartógrafo sob forma de dados brutos ou de maquetes, vai ser interpretada graças às técnicas cartográficas" (DENÈGRE, 2005).

A palavra informação corresponde portanto à descrição da natureza, do aspecto e dos atributos de um objeto assim como suas relações com outros objetos e fenômenos. É também um termo de tipo semântico. Quanto à palavra geográfica, ela corresponde à localização do objeto sob a superfície terrestre, descrita num sistema de referência explícito (sistema de coordenadas ou endereço postal); ela exprime intrinsicamente uma noção 
geométrica (DENÈGRE; SALGÉ, 2004). Podemos acrescentar que atualmente é indispensável completar essa definição de J. Denègre integrando a ela um terceiro componente: o tempo. Essa informação geográfica, que é doravante de fato uma informação espaço-temporal, indaga sobre o mundo que vivemos; ela é portanto indispensável de ser compreendida, de fazer aparecer o que está subjacente e de transmitir, de comunicar o que se mostra. Para isto, o mapa é fundamental. Mas um mapa não se constrói diretamente a partir da informação geográfica; a passagem do terreno à esta informação para enfim culminar num produto que exprima o conteúdo dessa informação - o mapa -, exige numerosas transformações que convém aqui recordar. A figura 1 mostra as diferentes transformações para passar do terreno ao mapa.

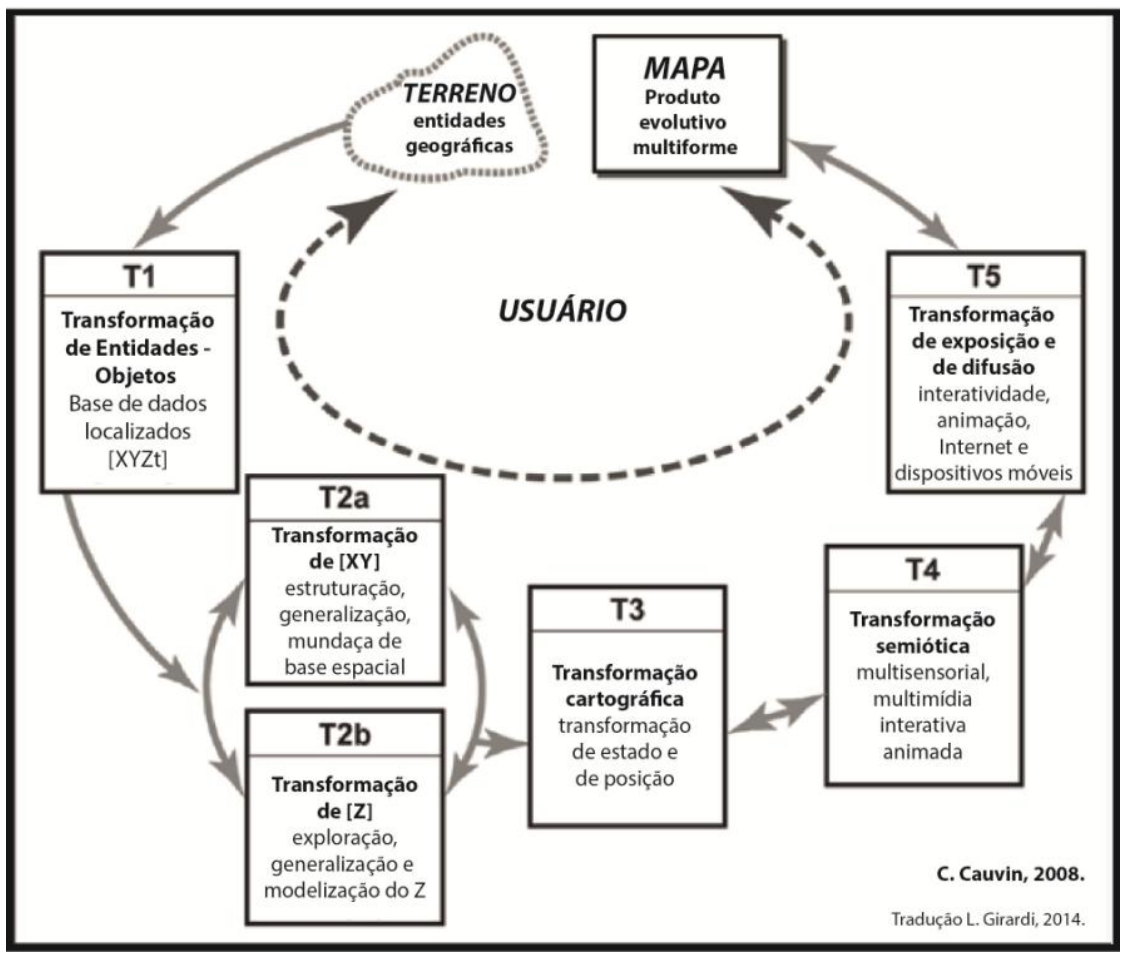

Figura 1. O mapa, processos de transformações em evolução

No entanto, essas transformações não são rígidas de forma conclusiva. Elas evoluem e as novas tecnologias as enriquecem, aprimoram-nas conduzindo à uma melhor compreensão e uma melhor transmissão da informação geográfica.

O objetivo desta comunicação é mostrar certos aportes das tecnologias atuais à Cartografia, disciplina que exprime de maneira privilegiada a informação geográfica. A ênfase será posta num primeiro momento na renovação dos tratamentos de dados tributários e sua representação culminando na sua animação. A segunda parte sublinhará a riqueza do 
multimídia, particularmente pela utilização de animações e de nossos diferentes sentidos. Enfim, a terceira parte mostra o aporte de dados de satélites e da modelização.

\section{A cartografia temática e o digital}

A primeira grande transformação da Cartografia, no início da segunda metade do século XX, está associada à revolução digital, quer dizer à passagem do modo analógico ao modo digital, induzida pela aparição dos computadores e da informática.

\section{Novas funções graças às Bases de Dados Localizados}

A Cartografia, como outras disciplinas, sofre as consequências da passagem do analógico ao digital, como R.F. Tomlinson analisa o impacto em um artigo de 1988 (TOMLIMSON, 1988). Esta passagem permitiu aos cartógrafos, num primeiro momento, reproduzir aquilo que eles faziam manualmente, automatizando a cadeia de produção (rapidez, exatidão, etc.), melhorando e transformando certos procedimentos. Num segundo momento, ela permitiu a abertura de oportunidades quanto aos dados, sua estruturação, sua gestão, seu tratamento e sua modelização conducentes, entre outros, às bases de dados localizados e aos Sistemas de Informação Geográfica (SIG) (CAUVIN, ESCOBAR e SERRADJ, 2008b).

É graças à essa base de dados localizados, elemento fundamental na Cartografia, e à informática, que as transformações cartográficas (figura 1) são possíveis e revelam elementos escondidos, de comunicá-los, e permitem ao usuário final de explorá-los em diferentes domínios (figura 2). É evidente que certas transformações não podem ser aplicadas sem a potência dos computadores, entre elas as Transformações Cartográficas de Posição (TCP). Esses mapas que aos olhos do neófito são como gadgets à primeira vista, de fato são métodos e por vezes modelos. Eles permitem revelar características não visíveis diretamente, úteis tanto à pesquisa que para o planejamento do território ou da comunicação (CAUVIN, ESCOBAR e SERRADJ, 2008a).

Todas essas funções do mapa se desenvolvem graças à informática que conduziu a utilização de tratamentos estatísticos para os dados da base e da renovação das transformações cartográficas, como podem ilustrá-las certos estudos sobre a acessibilidade. Assim, a acessibilidade potencial de uma rede (rodoviária, ferroviária...) pode ser posta em evidência 
pelo cálculo de índices marginais da matriz de tempo de acesso e o mapa em isolinhas associado. Com um tratamento mais avançado, como a Análise Fatorial de Correspondências, uma hierarquia de lugares pode ser demonstrada e visualizada por uma cartografia pontual com envelope. Esses procedimentos são muito comuns, por isso preferimos dar ênfase aqui em métodos antigos completamente renovados graças à informática.

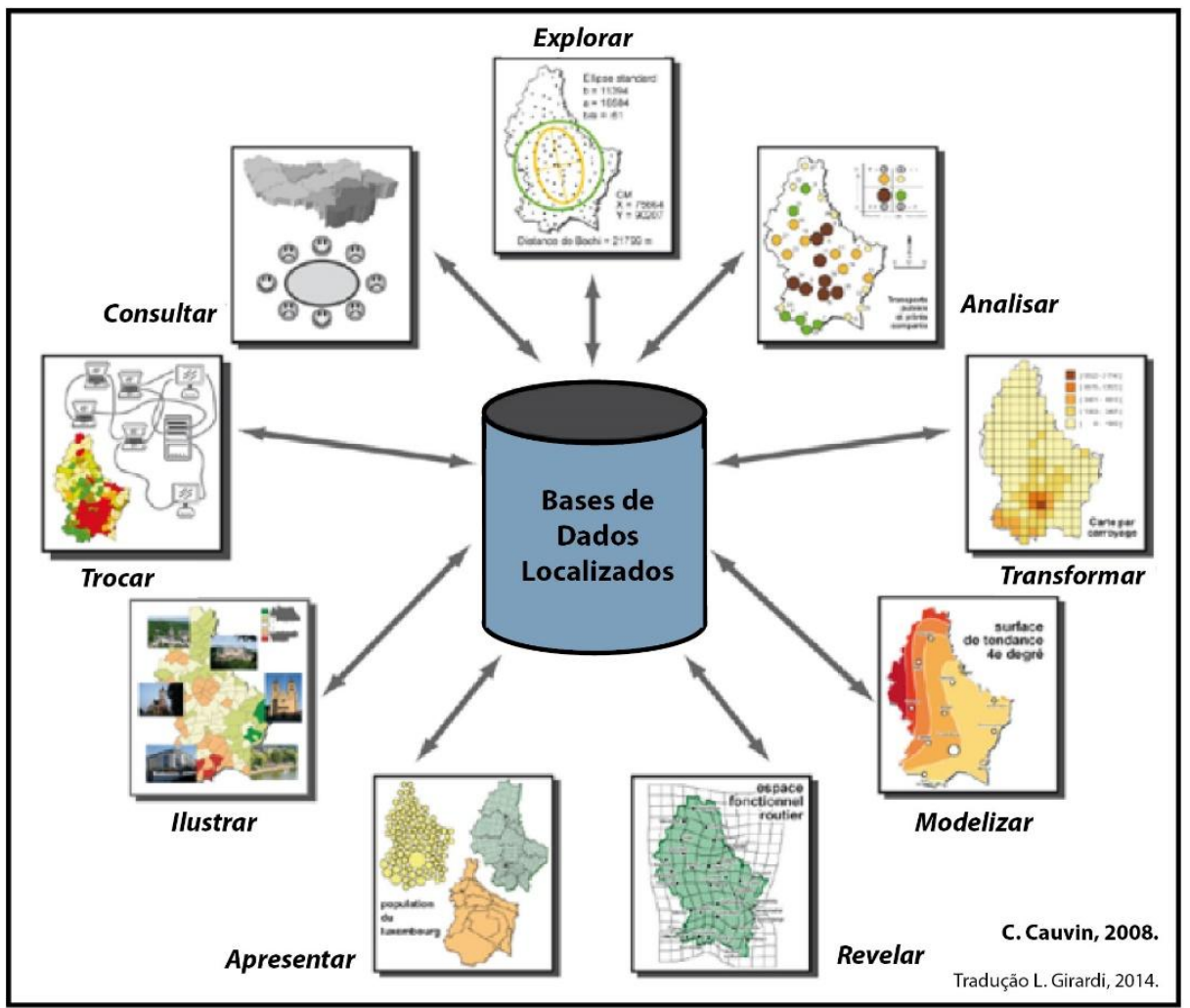

Figura 2. No core da produção cartográfica, a base de dados localizados.

\section{Métodos antigos renovados}

Um segundo nível de transformações renova tratamentos e representações apoiando-se nas TCPs, mais conhecidas sob o termo, frequentemente mal utilizado, "anamorfose". A acessibilidade fornece exemplos excelentes. A matriz de acessibilidade é tratada em um conjunto de duas etapas sucessivas, como mostra a figura 3.

Num primeiro momento, graças a um método da família de análise multidimensional de proximidades, com a ajuda do aplicativo KYST (KRUSKAL, YOUNG e SEERY, 1977), a matriz é transformada em uma configuração, isto é, um gráfico cartesiano das posições relativas dos lugares em tempo de acesso, como ilustram as figuras $4 a$ e $4 b$. 


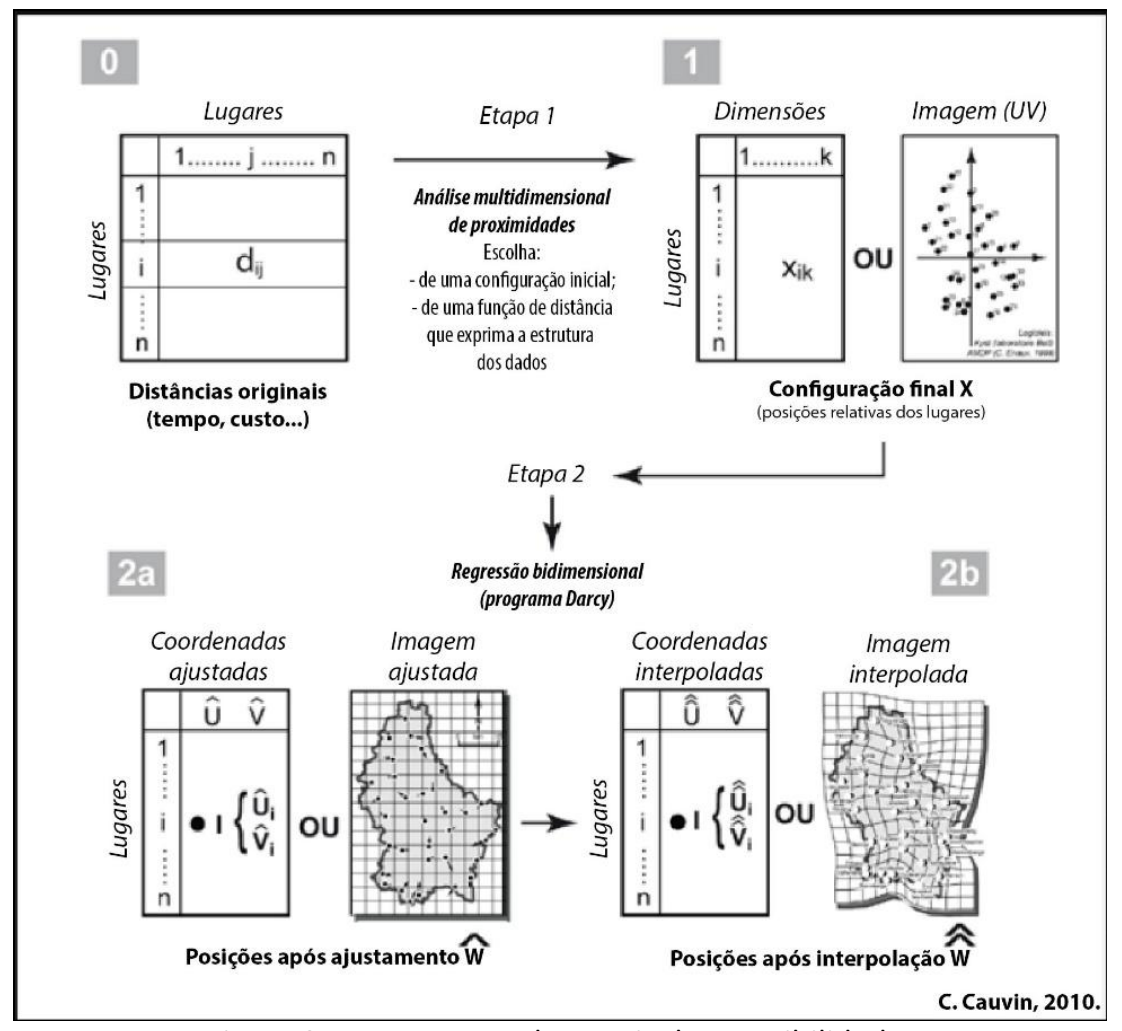

Figura 3. Tratamentos da matriz de acessibilidade.

Num segundo momento, a configuração é comparada ao espaço geográfico de referência graças a uma transformação cartográfica de posição diferencial (TOBLER, 1977). Esse método, ilustrado pelas figuras $5 a$ e $5 b$, culmina na produção de dois mapas: o primeiro representa os vetores de deslocamento entre as posições de referência e as posições em tempo de acesso dos lugares, e o segundo, deformado, exprime o espaço funcional ligado ao modo de locomoção estudado.

Como mostram os mapas, as TCPs apresentam e modelizam de maneira inabitual os espaços funcionais que praticamos a partir de nossos deslocamentos. Esses procedimentos constituem-se de ferramentas de exploração e de compreensão. Eles fazem igualmente o papel de ferramenta de comunicação em particular, na medida em que são completados e melhorados por animações. Esses últimos, componentes completos dos procedimentos multimídia, servem igualmente para tornar os mapas dinâmicos, integrando, entre outros, o tempo.

Assim, a revolução digital que atingiu a Cartografia transformou esta disciplina muito além dos melhoramentos técnicos que podia-se esperar. Outras disciplinas nasceram (os SIGs e, além, a geomática e as geociências), as quais não abordaremos aqui; o mapa mudou seu 
estatuto: ele não é mais definitivo e fixo, ele se tornou dinâmico, virtual, temporal, manipulável, pemitindo aos usuários não fazerem escolhas a priori, como vão mostrar os aportes multimídia.

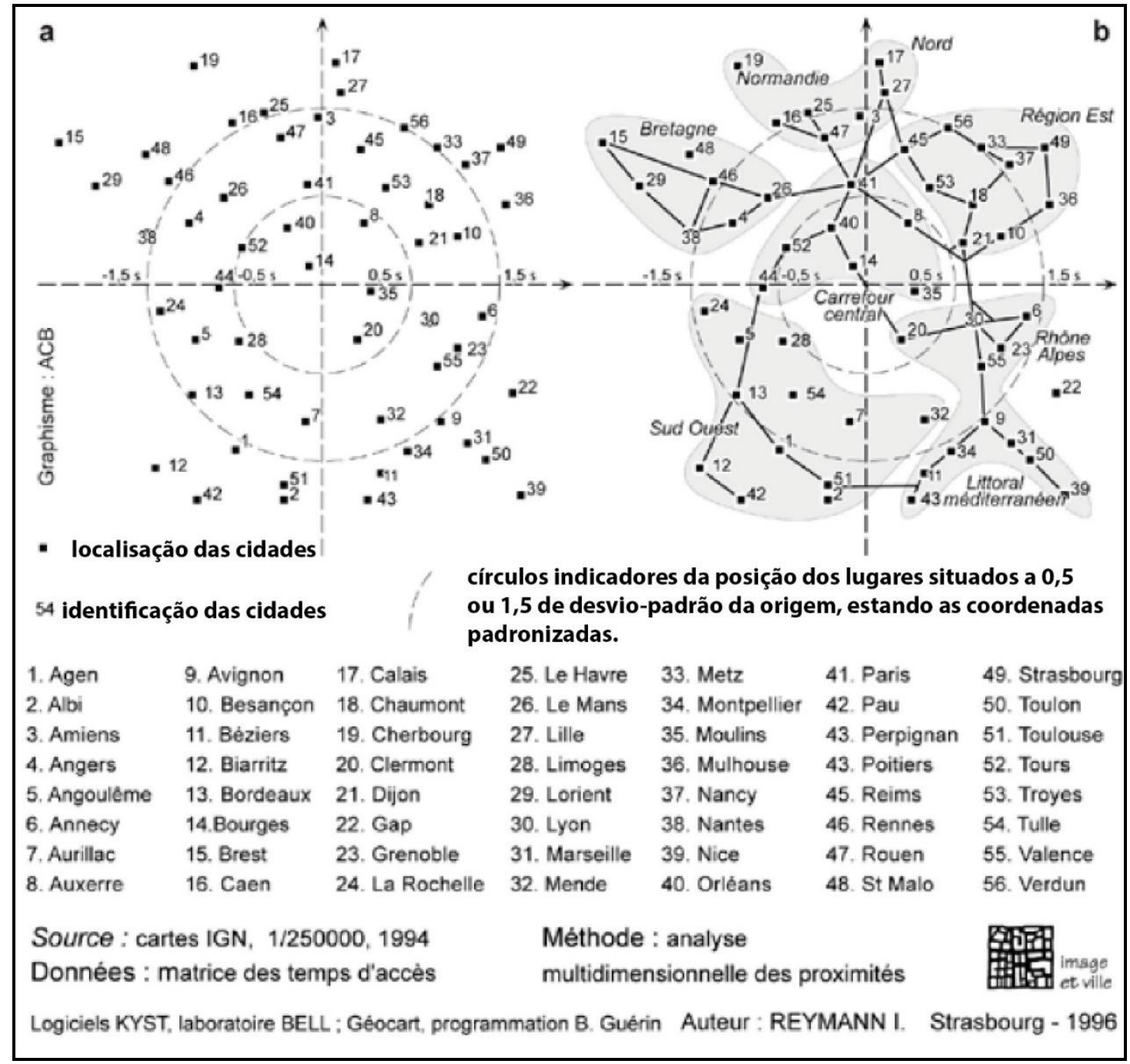

Figura 4. a: Configuração dos lugares em "tempo de acesso"; b: Esquema de interpretação das diferentes zonas de acessibilidade. 


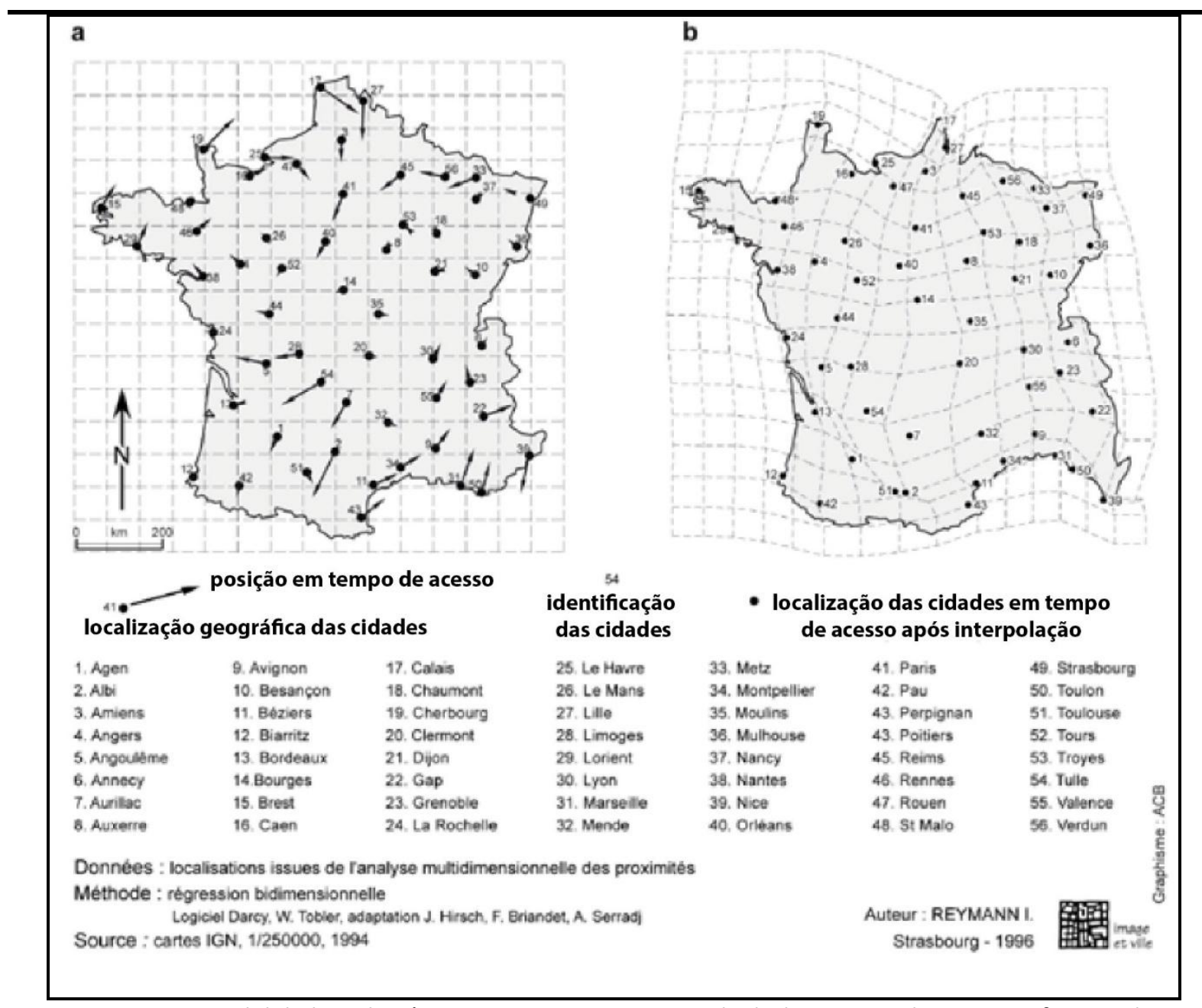

Figura 5. Acessibilidade rodoviária na França. a: os vetores de deslocamento; b: o espaço funcional.

\section{O multimídia e a Cartografia}

O multimídia, segunda revolução que tocou a Cartografia em profundidade, oferece novas ferramentas a esta disciplina e se inscreve no contexto cultural e social atual. Com efeito, o público é cada vez mais habituado a ver imagens, gráficos, mapas meteorológicos, etc., uma multiplicidade de mídias. O mapa deve dar conta dessas mudanças e, qual seja o destinatário, nele é indispensável apresentar e difundir a informação geográfica de maneira atrativa e intuitiva de modo que permita uma compreensão rápida e simples. A visualização de dados espaciais não é mais limitada pelas técnicas, e a questão essencial torna-se a seguinte: qual e a mídia que melhor se adapta à tarefa assumida? Com efeito, o leque de possibilidades se alarga regularmente, ele integra cada vez mais animações, interatividade e componentes sensoriais, e cada uma dessas ferramentas assegura uma função específica. 


\section{Contribuição da animação à informação geográfica}

A animação é um componente essencial dos procedimentos multimídia porque ela introduz movimento aos documentos apresentados. Desde 1989, R. Roncarelli fornece uma definição bastante técnica e completa da animação: "a animação pode ser definida como um procedimento de criação de uma ilusão de movimento ou de passagem graças à afixação rápida de uma sucessão de imagens como num filme ou um vídeo" (RONCARELLI, 1989). A noção de animação se tornou corrente a partir da invenção do cinema, e depois pela aparição do vídeo e da televisão onde, todo dia, o espectador vê desfilar, entre outros, mapas animados indicando as variações do tempo ao curso de 24 horas, na França, na Europa ou no mundo. A animação é, de uma parte, "a ação de animar, de dar à vida, o movimento" e, de outra parte, "colocar em movimento desenhos ou figuras que dão a ilusão da vida", ambos significados ligados porque "animar é literalmente trazer à vida" (FOLEY et al, 1995).

Em Cartografia, a animação apresenta imagens distintas que se sucedem numa sequência lógica percebida pelo olho. Diferentes tipos de animações são possíveis na medida enquanto elas exprimem o tempo (animações temporais, processuais) ou não (animações temáticas estruturais). A animação da rede ferroviária francesa em 1994 constitui um exemplo de animação estrutural (REYMANN e CAUVIN, 1996), (CAUVIN e REYMANN, 1996), a visualização da passagem do espaço de referência ao espaço funcional (figura 6).
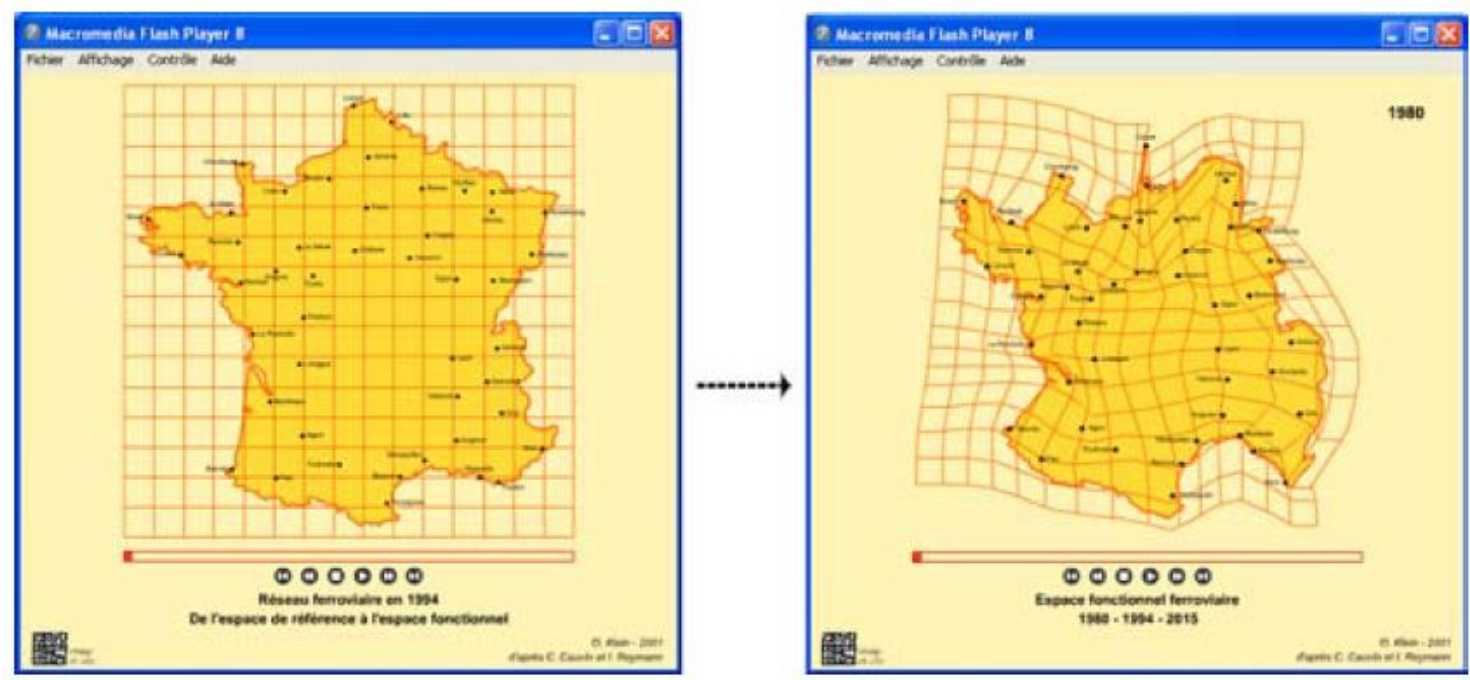

Figura 6. Animação temática estrutural: do espaço de referência ao espaço funcional ferroviário. 
As animações processuais colocam em evidência as mudanças no tempo e facilitam as simulações como mostram os dois exemplos que se seguem. O primeiro concerne à acessibilidade dos transportes em comum numa duração de 24 horas pela cidade de Belfort (figura 7); o segundo traz uma simulação da acessibilidade ferroviária na França entre 1980 e 2015 (figura 8).

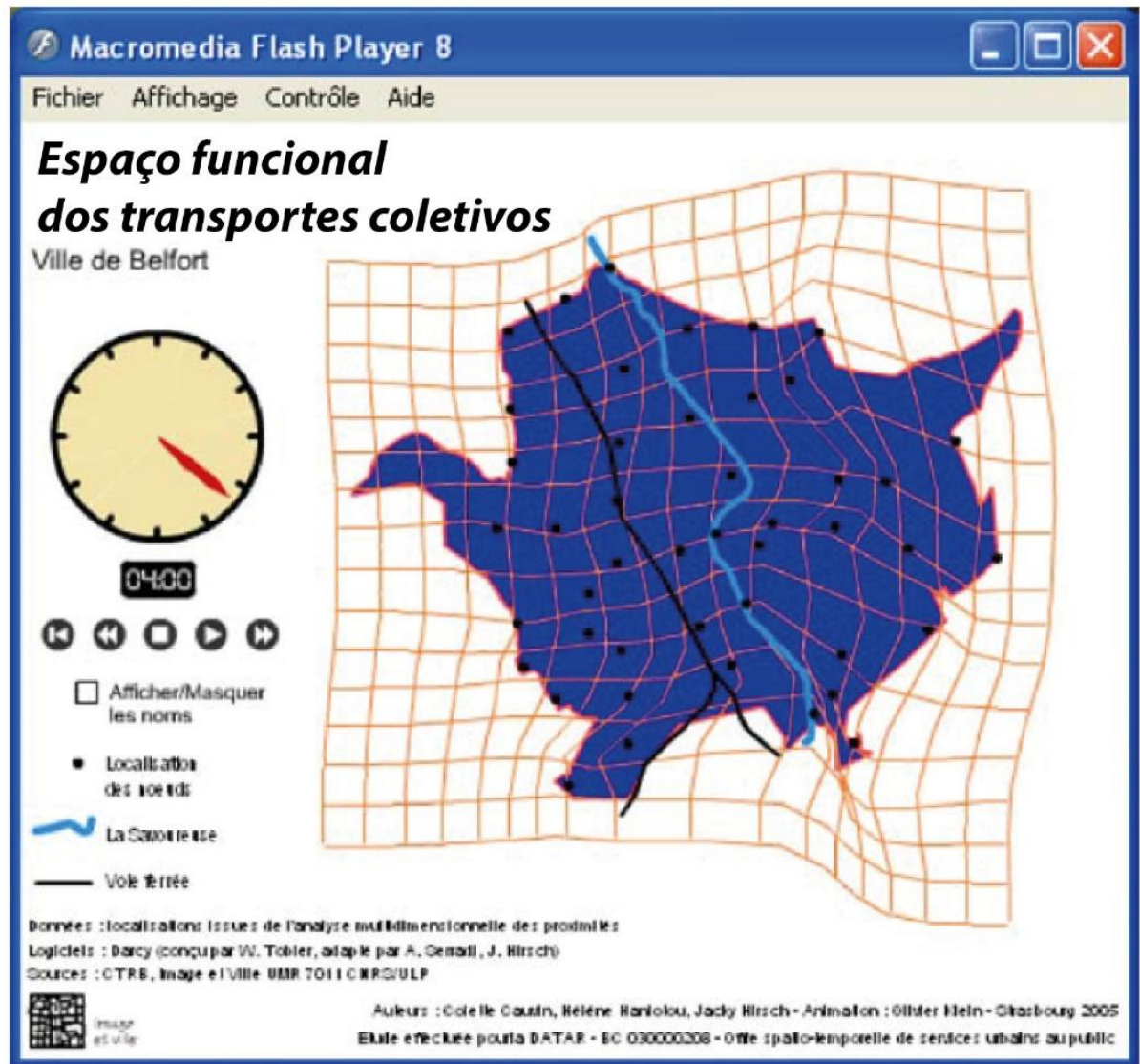

Figura 7. Animação temática processual: acessibilidade na cidade de Belfort ao curso de 24 horas nos transportes coletivos.

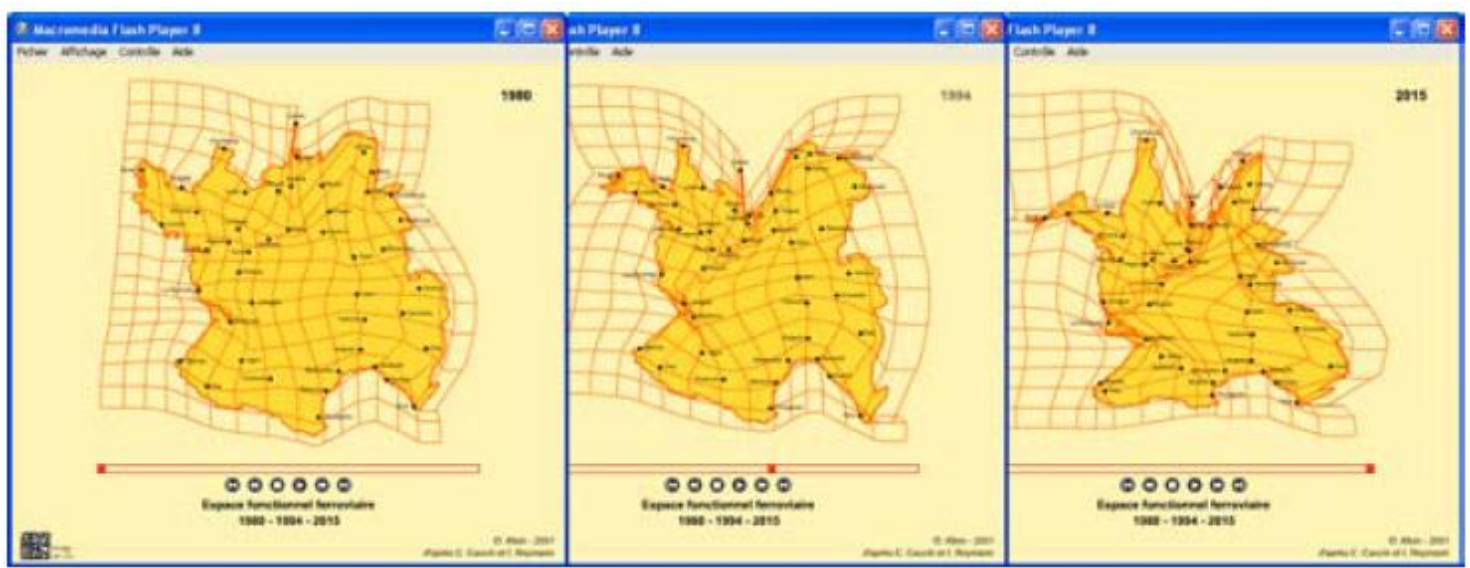

Figura 8. Animação temática processual: simulação da acessibilidade ferroviária entre 1980 e 2015 na França. 
Os mapas animados descrevem assim as mudanças de conteúdo, de posição e de tempo, e têm o poder de fazer aparecer as inter-relações de diversos componentes, pela apresentação de imagens cartográficas distintas que rapidamente aparecem uma atrás da outra, numa ordem lógica que se sucede em sequência coerente à percepção do olho. A multimídia traz igualmente outras oportunidades ao fazer apelo aos diferentes componentes sensoriais.

\section{Uma nova oferta semiótica: a utilização de diferentes sentidos}

O mapa é considerado de maneira prioritária como visual e por definição fazem apelo à nossa visão. Durante muito tempo, foi preciso considerar outros meios de comunicação quando o destinatário não dispunha da visão. Assim, os mapas para quem não ou mal enxerga fazem apelo ao toque. Mas atualmente outras possibilidades aparecem.

O uso do multimídia permite e faz apelo a todos os sentidos do utilizados e não mais se limita à visão; assim o som, o toque, o odor podem ser, teoricamente, introduzidos num mapa (figura 9). O acréscimo desses sentidos conduzem ao desenvolvimento de uma cartografia multimídia, multissensorial, como sugere Blok (BLOK, 1998). Todos os sentidos não foram ainda realmente testados, ao nosso conhecimento, com exceção da visão, e até este dia, os ensaios trouxeram essencialmente o toque e a audição; para o olfato e sobretudo o paladar, estão apenas começando.

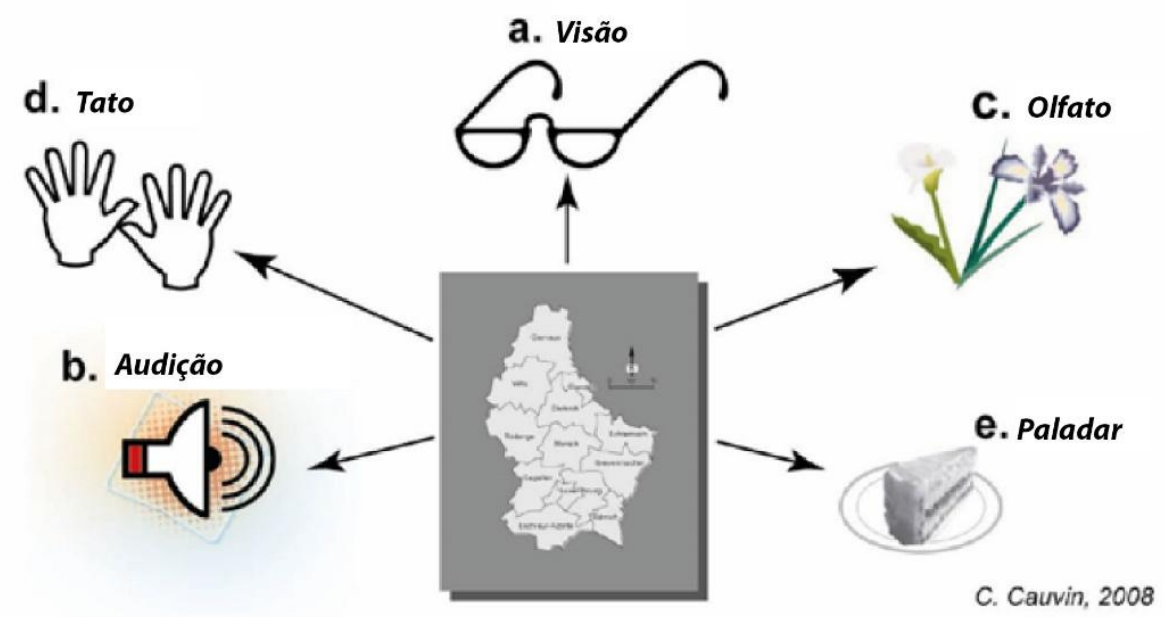

Figura 9. A cartografia e os cinco sentidos.

Nesta comunicação, escolhemos desenvolver um pouco mais o aporte do som em cartografia porque, assim como diz J.D. Bagot (BAGOT, 1999), "a visão e a audição são as 
duas modalidades sensoriais com mais performances e mais úteis ao homem para aprender seu meio ambiente", e em seguida tratar dos mapas que exprimem esse meio ambiente.

O não-uso ou o mal uso do som, sublinhado por certos autores, é injustificado, porque numerosos índices mostram que o som é largamente utilizado pelos homens afim de compreender o mundo que os cercam, ao mesmo tempo que imagens as quais ele se combina (CHION, 1994 in COOLEY, 1998). Uma imagem sem o som não é interpretado, nem memorizado da mesma maneira que um som é associado. M. Chion considera esse efeito cumulativo como uma percepção global porque ele corresponde a uma relação imediata e necessário entre uma coisa que vemos e outra que entendemos. J.C. Muller e H. Scharlach (MULLER e SCHARLACH, 2001) desenvolveram aplicativos variados na utilização do som em cartografia, apoiando-se em trabalhos de J.B. Krygier (KRYGIER, 1994; KRYGIER, 1996). Estes trabalhos conectam espacialmente a modelização do som e sua expressão semiótica. Neste exemplo, os autores apelam a sons realistas que reproduzem barulhos sob forma de som modelizado, que fazem parte da vida cotidiana (o canto dos pássaros, o barulho de trens e automóveis). Assim, sobre uma fotografia aérea (figura 10), são marcados de maneira esquemática os elementos essenciais da paisagem: rotas principais, vias férreas, parques, zonas residenciais. Quando nos deslocamos com a ajuda do cursos sobre esse espaço, ouvimos o barulho do trem perto dos trilhos do caminho de ferro, dos carros ao longo da rodovia e dos pássaros no parque. Há variantes de volume e natureza segundo o modelo de barulho subjacente e sua intensidade.

Esse tipo de cartografia pode ter aplicações variadas, desde o planejamento do território até melhoramentos na qualidade de vida de certos quarteirões urbanos à prospecção imobiliária, na busca de moradias calmas e tranquilas pelos locatários ou comprador potenciais.

Apesar dessas inovações, certos problemas necessitam de outras respostas. Assim, o conhecimento o mais próximo possível da realidade de densidades ou da evolução da ocupação do solo não podem ser obtidos com os dados que são disponibilizados. Recorrer a imagens de satélites, fotografias aéreas e bases de dados topográficos é crucial e, face à multiplicidade de informações que se apresentam, uma modelização se impõe. 


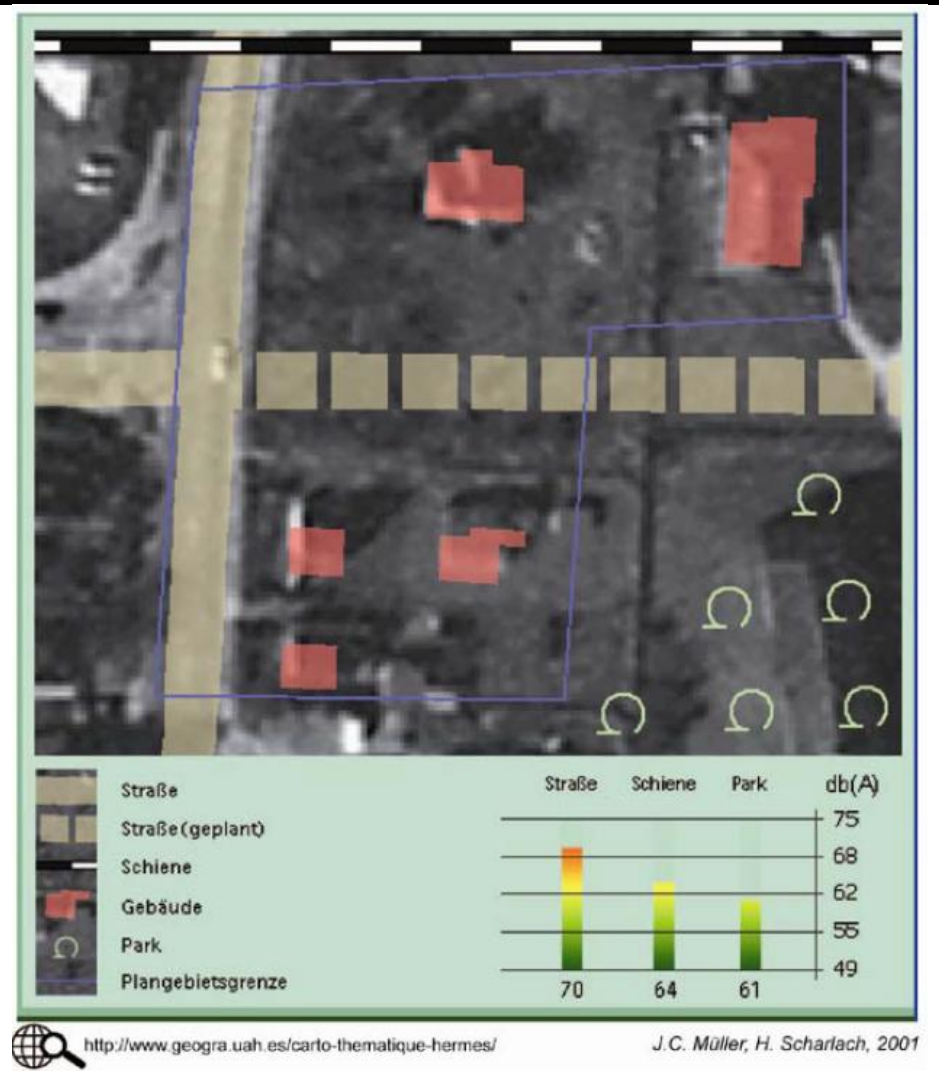

Figura 10. Associação de imagem e do som.

\section{Multiplicidade/diversidade de dados e modelização: uma outra via de desenvolvimento da cartografia}

Assistimos no mundo, nos últimos quarenta anos, um crescimento urbano cada vez mais rápido. Ele é acompanhado de um movimento de periurbanização importante, tornando difícil a previsão e a gestão pelos tomadores de decisão das coletividades locais ou territoriais. Como aponta M. Balestra et al., a contração e a deslocalização de populações e de atividades de cidades centrais na direção das periferias traduzem pelo crescimento e dispersão de superfícies construídas às custas de espaços naturais e agrícolas (BALESTRA, 2008). A fim de planejar essa argumentação sobre as superfícies minerais artificiais, modelos essencialmente cartográficos, baseados em autômatos celulares (AC) ou sistemas multiagentes (SMA) constituem de ajudas novas para a decisão. Essa modelização de sistemas espaciais por AC e SMA permite reproduzir uma eventual auto-organização espacial.

Esses dois modelos permitem introduzir numa base de dados geográficos os "agentes" ou "células" que interagem no território modificando-o, e sendo eles mesmos modificados pelo ambiente em retroação. No SMA, os agentes interagem entre si e no território; nos AC, as 
interações são apenas no território, na vizinhança. Qual seja o modelo utilizado, é assim possível propor cenários teóricos se relacionando a processos dinâmicos, como mostram os dois exemplos presentes aqui. Eles trazem a evolução da ocupação do solo graças a imagens de satélites, fotografias aéreas, bases de dados topográficos e uma modelização utilizando os autômatos celulares ou os sistemas multi-agentes.

\section{Modelização por autômatos celulares}

O MOLAND foi iniciado em 1998 no projeto MURBANDY (Monitoring Urban Dynamics) e desenvolvido pelo RIKS (Research Institute of Knowledge Systems) no quadro de contrato financiado pelo Centro Comum de Pesquisa da União Europeia (JRC: Joint Research Centre). É uma ferramenta prática destinada ao planejamento urbano e regional cujo objetivo principal é de avaliar, gerir e modelizar o desenvolvimento urbano e regional, passado, presente e futuro, numa perspectiva de desenvolvimento sustentável, apoiando-se em bases de dados de ocupação do solo e de redes de transporte de variadas cidades e regiões europeias (BARREDO, KASANKO, McCORMICK e LAVALLE, 2003). O MOLAND baseia-se na hipótese de que nenhuma predição exata é possível para os sistemas socioambientais complexos. Assim, ele foi concebido como um modelo de simulação espacial, integrado num Sistema de Auxílio à Decisão, para estimular a reflexão e facilitar a discussão (BARREDO, LAVALLE, KASANKO e McCORMICK, 2003). Sendo um modelo genérico, MOLAND parte das hipóteses de que as cidades se parecem até certo ponto, que elas evoluem guiadas pelos mesmos processos e que são as condições topográficas, a geometria de redes de transporte e a legislação específica de cada cidade, que as diferenciam (ENGELEN, WHITE, ULJEE et al., 2004). O modelo visa à simular diferentes cenários futuros de ocupação do solo. Sua abordagem inclui três etapas principais: a constituição de dados de partida, a calibragem do modelo e a integração de dados cartográficos.

Os resultados obtidos se apresentam sob forma de mapas e de estatísticas. O principal documento é um mapa de ocupação do solo pela data desejada, em geral vinte anos depois da data do mapa mais recente introduzido no começo (figura 11). Índices, mapas e tabelas com as estatísticas e as informações associadas sobre a acessibilidade, os riscos, a fragmentação dos elementos que compõe a paisagem; animações mostrando as mudanças da ocupação do solo completa o inventário de resultados (figura 12). 


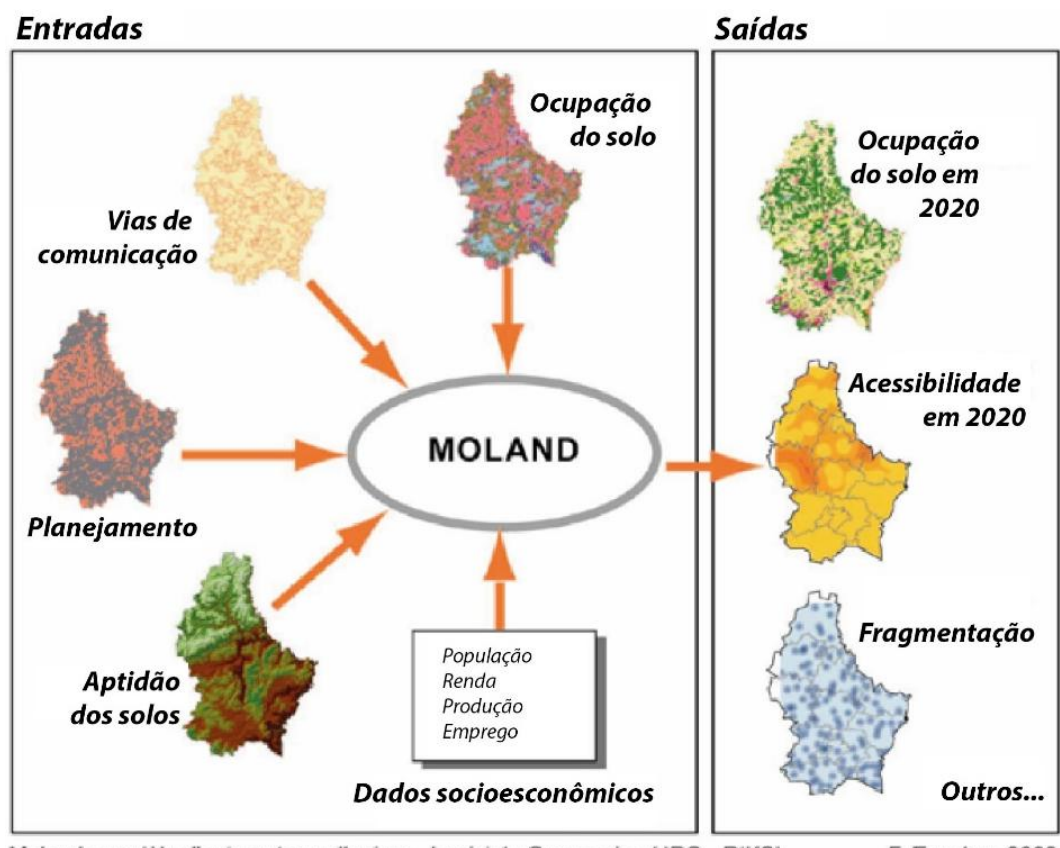

Moland : modèle d'automates celluaires - Logiciel : Geonamica (JRC - RIKS) F. Escobar, 2008 Figura 11. Ilustração das etapas do MOLAND e resultados alcançados.

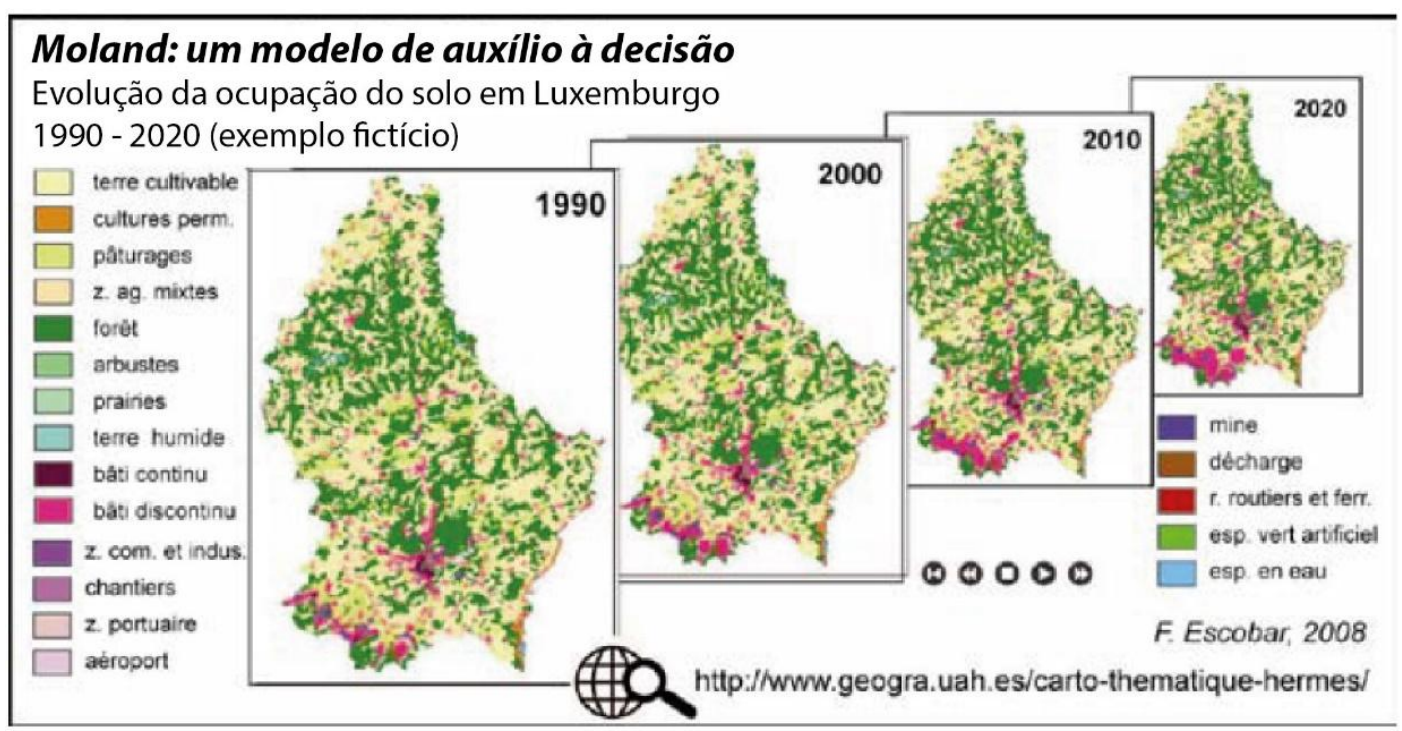

Figure 12. Animação de resultados do modelo MOLAND aplicado a Luxemburgo em diferentes datas (dados fictícios).

Assim, os AC enriquecem a informação geográfica ao criar novas informações para o futuro, se exprimindo diretamente pelos mapas, que permitem visualizar rapidamente e simplesmente as mudanças de ocupação do solo. 


\section{Modelização pelos sistemas multi-agentes (SMA)}

Como assinalamos antes, um SMA enfatiza a modelização de entidades, os agentes, e as relações que eles mantêm entre eles e com o meio ambiente. Estes são agentes que se deslocam por um espaço e que são capazes de se organizar para cumprir as suas funcionalidades. Para J. Ferber, um SMA é composto de um ambiente E (espaço com uma métrica); de um conjunto de objetos localizados passivos (ocupante de uma posição em E); de um conjunto de agentes; de um conjunto de relações que unem esses objetos; de um conjunto de operações que permitem aos agentes perceber e manipular os objetos; de operadores responsáveis por representar a implementação dessas operações e a reação do mundo a esta tentativa de mudar (a que chamamos as leis do universo) (FERBER, 1995). Assim, um agente é um elemento móvel que pode se deslocar no meio ambiente (E). Ele é reativo, age de modo autônomo e pode perceber seu ambiente e responder aos estímulos externos. Ele é proativo no sentido dele poder tomar a iniciativa de começar uma interação com outros agentes ou modificar seu ambiente. Enfim, como ele é pequeno em relação ao tamanho do sistema, suas ações não podem ter efeitos globais sobre (E), porque estes últimos são o resultado de ações acumuladas de todos os agentes (GIL QUIJANO, 2007). Em geografia urbana, como aponta L. Sanders (SANDERS, 2006), a problemática pode ser de ordem intra ou interurbana, onde pode-se distinguir três níveis ou escalas de trabalho:

$\checkmark$ o nível micro corresponde aos indivíduos, aos domicílios, às empresas... descritos por características qualitativas ou quantitativas;

$\checkmark$ o nível meso pode ser representado pelos quarteirões de uma perspectiva intraurbana ou pelas cidades no caso de uma perspectiva interurbana;

$\checkmark$ o nível macro é aquele da cidade numa perspectiva intra-urbana ou do sistema de cidades no caso de uma perspectiva interurbana.

\section{Princípios de base das aplicações}

A fim de ilustrar do SMA em geografia urbana, vamos apresentar duas aplicações conduzidas numa escala meso de estudo, em dois sítios geográficos e temáticos distintos. O primeiro concerne a evolução de zonas industriais em um quarteirão da cidade de Orleans, a segunda o desenvolvimento de uma habitação coletiva em um quarteirão da cidade de Estrasburgo. 
Os resultados dos trabalhos, que se encaixam dentro do quadro do projeto GeOpenSim cujo LIVE é parceiro, foram obtidos a partir de dados topográficos históricos. O objetivo dos dois estudos é realizar, por meio do SMA, uma modelização do ponto de vista morfológico das propriedades auto-organizativas dos sistemas complexos urbanos. Do mesmo modo, o SMA proposto comporta uma hierarquia de agentes topográficos (edifícios, vias, cursos d'água, ilhotas) que podem ser construídos, modificados, fundidos, decupados, reestruturados e destruídos ao curso do tempo. O comportamento de cada agente é controlado por um conjunto de regras de evolução, de restrições e ações associadas. A questão principal desses dois estudos envolve métodos de povoamento, que permitem a criação de novos agentes respeitando certa organização espacial e certo processo de construção (CURIE, MAS, PERRET et al., 2010).

Antes de passar aos resultados dos dois estudos, é necessário explicitar em poucas palavras o que se entende por trás da "noção de povoamento" e o "método de povoamento". A noção de povoamento designa o processo de preenchimento do espaço, em particular ilhotas, por objetos geográficos como edifícios ou vias. Um método de povoamento especifica o desenrolar do processo de preenchimento. Os métodos genéricos de povoamento para a construção de edifícios ao seio de uma ilhota urbana, define-se um conjunto de medidas morfológicas sobre a ilhota e os edifícios (CURIE, MAS, PERRET et al., 2010). Após esses trabalhos (CURIE, MAS, PERRET et al., 2010), a determinação de métodos de povoamento foi estabelecida por geógrafos a partir de análises visuais de cartas topográficas de diferentes datas, como mostra a figura 13 do exemplo de Orleans. 0 objetivo desse trabalho era fazer surtir o raciocínio posto em prática, permitindo colocar em evidência os parâmetros característicos na construção de métodos de povoamento. Isto se relaciona a um tradicional comentário de mapa em geografia, reduzido à escala do quarteirão ou da ilhota.

Esta análise não coincide com o nível de análise necessário pelo sistema, dada a dificuldade de formalização de regras qualitativas, a priori simples para o geógrafo, não são simples de transcrição em regras quantitativas utilizáveis para a simulação.

Assim, após a utilização, segundo cada caso, das principais características dos métodos de povoamento, mostraremos os resultados obtidos após a simulação em Orleans e Estrasburgo. 


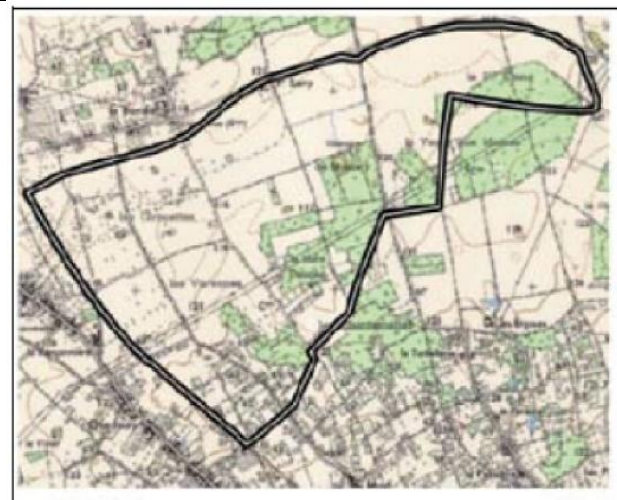

(a) 1957

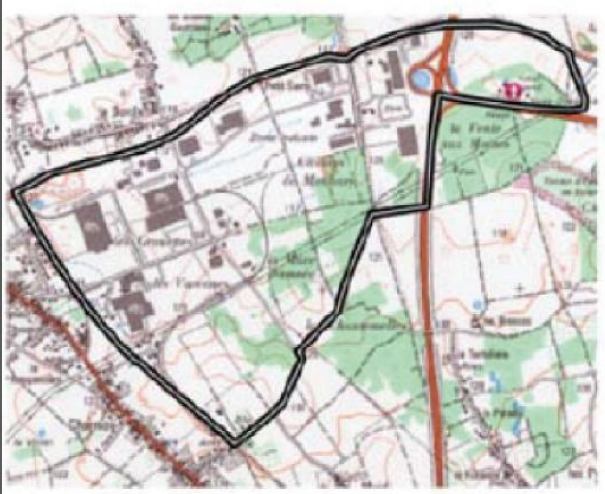

(c) 1989 - complemento

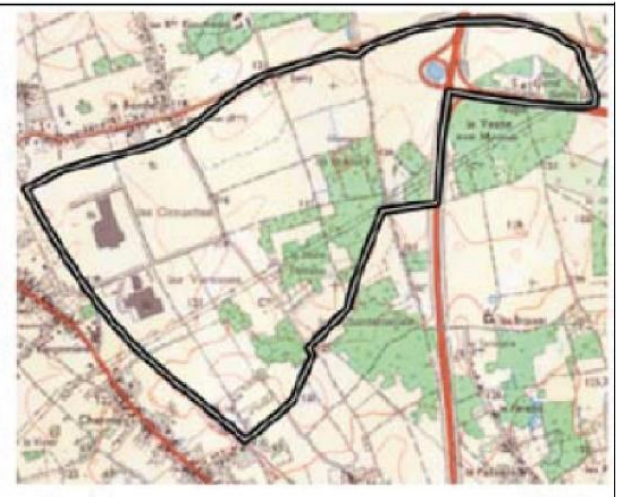

(b) 1978 - inicialização

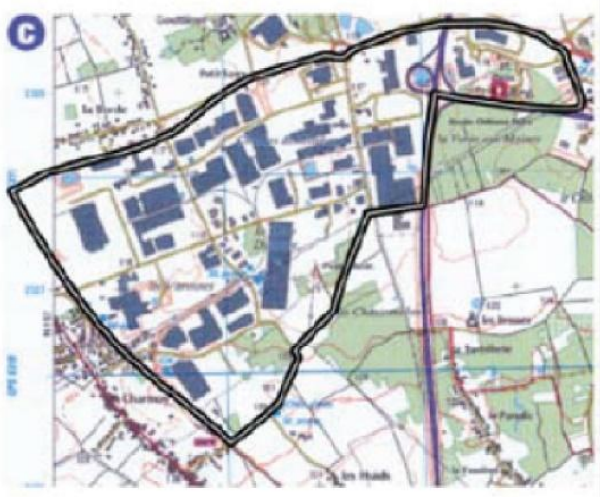

(d) 1999 - finalização

Figura 13. Exemplo da evolução de zonas industriais de Orleans (CURIE, MAS, PERRET et al., 2010).

\section{RESULTADOS}

Esses dois modelos de simulação fornecem, segundo os métodos propostos, resultados muito próximos os quais vamos expor brevemente.

\section{Evolução das zonas industriais em Orleans}

As zonas industriais são em geral localizadas em periferias da cidade próximas a vias de comunicação, como vias férreas e os trevos rodoviários das estradas principais. Elas são constituídas de edifícios de grande tamanho e de formas variadas, portanto morfologicamente diferente do resto da cidade. Uma zona industrial da cidade de Orleans serviu como zona de teste. A comparação entre a realidade de 2007 (figura 14b) e o resultado da simulação para 2007 (figura 14c) mostra que a distribuição dos tamanhos dos prédios, assim como o posicionamento deles em relação à rodovia e entre eles, 
correspondem-se muito bem. No entanto, afim de melhorar o realismo dessa simulação, é necessário realizar ajustes sobre a forma, a orientação e a organização dos edifícios.

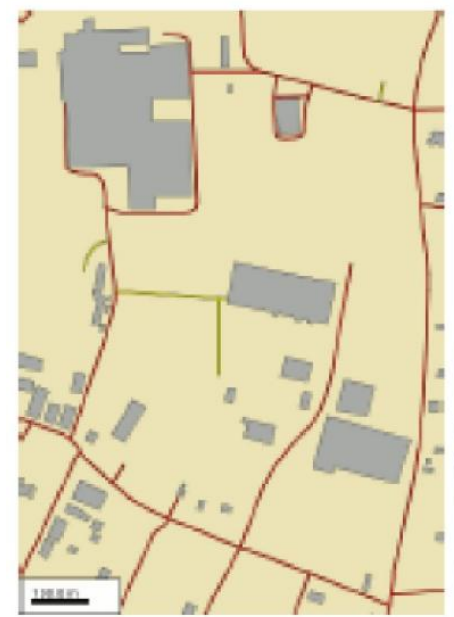

(a) estado inicial em 1989

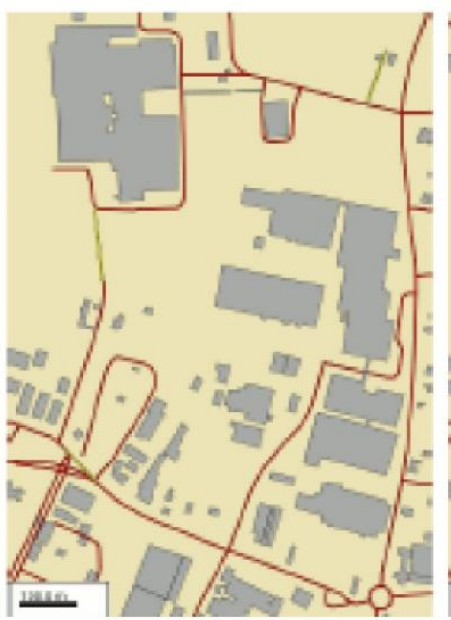

(b) estado final em 2007

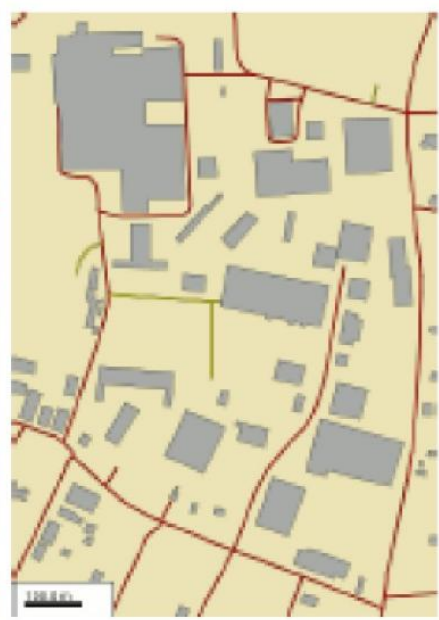

(c) simulação

Figura 14. Simulação de uma densificação com o método de povoamento: Zona industrial (CURIE, MAS, PERRET et al., 2010).

\section{Evolução de diferentes tipos de edifício em diferentes quarteirões de Estrasburgo}

Os diferentes tipos de edifício concernidos nesse estudo sobre Estrasburgo são as habitações coletivas do tipo "barras" e "grandes conjuntos". Os resultados das simulações, aqui também, são estimados satisfazendo o que concerne a forma e a posição dos edifícios simulados (figuras 15c e 15f), como para as zonas industriais, a orientação dos edifícios é melhorada.

Assim como indicam as simulações nas zonas de teste de Orleans e Estrasburgo, os métodos de povoamento propostos produzem bons resultados para a zona industrial e a habitação coletiva (barras e grandes conjuntos). A simulação da densificação do tecido urbano com ajuda do SMA promete, após refinamento de certas medidas e integração de outros tipos de edifício.

Esses modelos de simulação também produzem informação geográfica. Esse aqui mostrado sob forma de mapa é não somente útil para o gestor, planejador, agente imobiliários, etc., mas também interessante àqueles que desejam saber como evoluirá seu bairro ou ilhota no passar do tempo. De todo modo, necessitaria que essas simulações pudessem ser disponibilizadas e acessíveis para todos e em todos os lugares... o que nos leva ao "Web Mapping Server". 


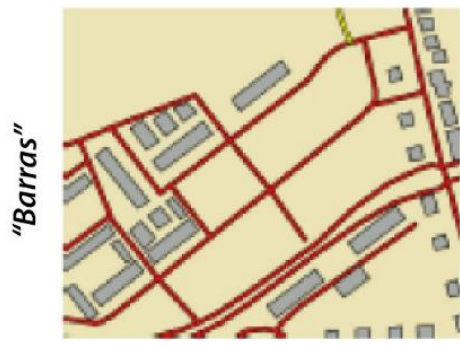

(a) estado inicial

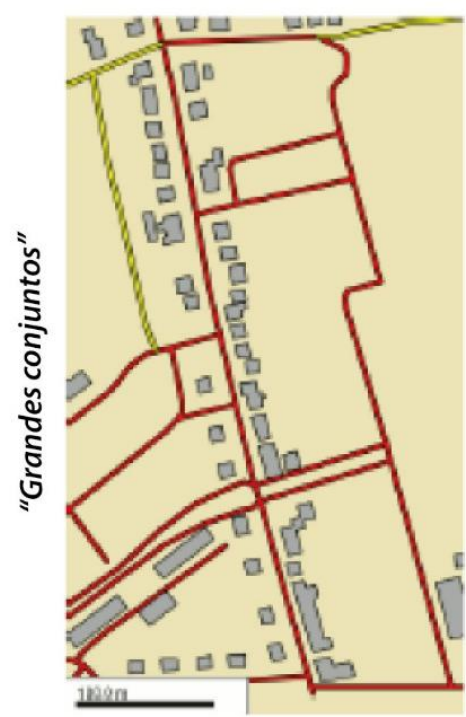

(d) estado inicial

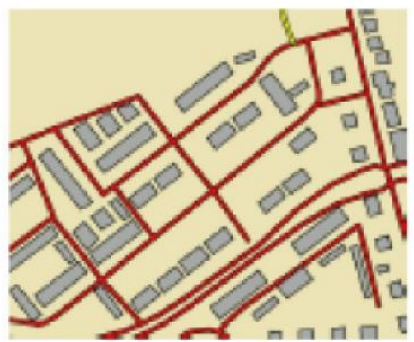

(b) estado final em 1989

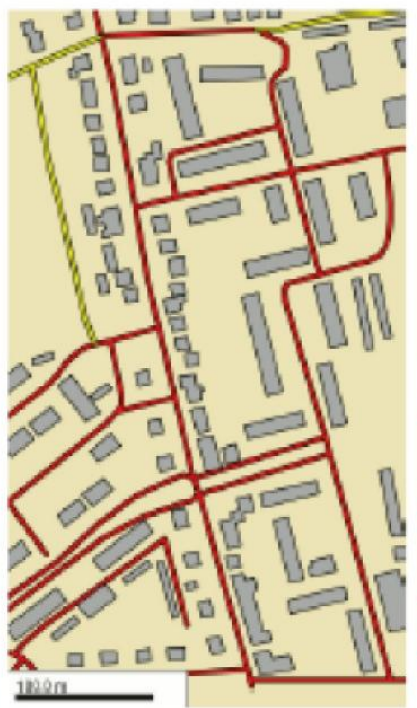

(e) estado final em 1989

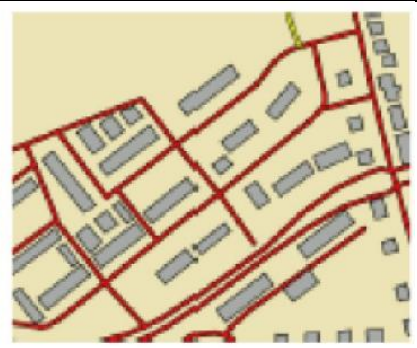

(c) simulação

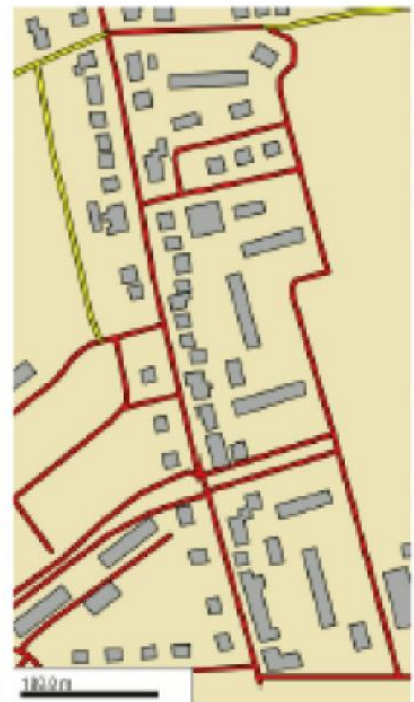

(f) simulação

Figura 15. Simulação de uma densificação com o método de povoamento: Habitações coletivas (CURIE, MAS, PERRET et al., 2010).

\section{A Informação Geográfica e a tecnologia "Web Mapping Server"}

Com efeito, uma necessidade essencial apareceu há poucos anos, o acesso à informação geográfica à distância, de compartilhá-la, de visualizá-la e utilizá-la por pessoas localizadas em lugares diferentes.

Um servidor de mapas é um programa de computador, localizado na web, que permite ao usuário interagir com uma base de dados SIG e representar a região escolhida sob a forma de um mapa (COLL, MARTINEZ, SANZ e IRIGOYEN, 2005). A tecnologia Web Mapping Server (WMS), associada à ferramentas específicas de metadados, constitui uma solução eficaz para a distribuição da informação geográfica na Internet (PADRON e ESCOBAR, 2006). Ela permite a gestão atualizada, a visualização da informação geográfica e a resposta a requisições à distância; assim, os dados podem estar localizados em qualquer lugar. Essa cartografia interativa é realizada à distância e está na interface de três disciplinas, que são a geografia, a informática e o desenvolvimento da web, como mostra a figura 16. A cartografia interativa 
deve ser simples, fluida, prática e intuitiva (DABERT, SERRADJ e HIRLEMANN, 2010). A interatividade permite ao usuário interagir com o mapa em função dos dados disponíveis e recuperar o resultado dessa interação, de modo reutilizável.

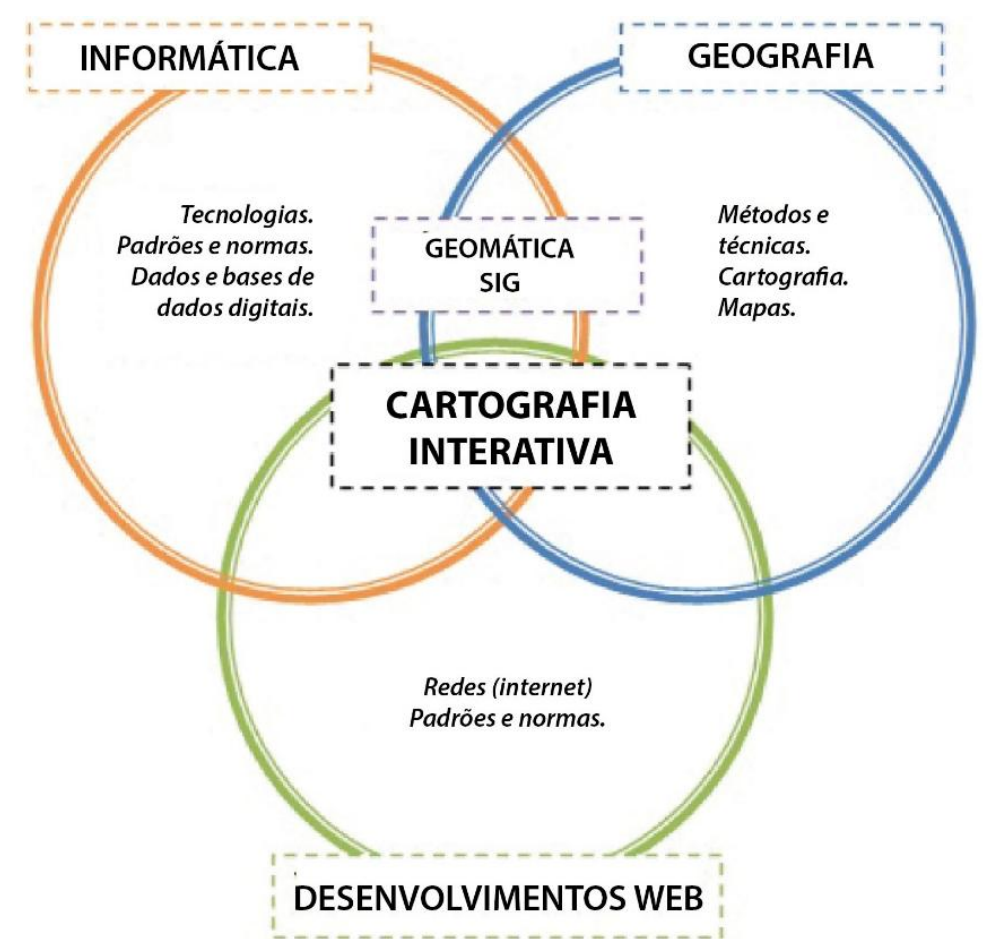

Figura 16: A cartografia interativa na interface de três disciplinas (DABERT, SERRADJ e HIRLEMANN, 2010 in PETERSON, 2005).

Dois exemplos vão permitir mostrar o interesse, um com ênfase na partilha de dados (DABERT, SERRADJ e HIRLEMANN, 2010) e o outro na prevenção de riscos.

\section{A aplicação: Servidor de Dados do Parque Natural Regional Vosges do Norte}

O objetivo do website de cartografia interativa do Parque Natural Regional (Pnr) Vosges do Norte é duplo, ele permite, de uma parte aos usuários, tornar pública as informações disponíveis e livres de acesso que interessam ao território (figura 17) e de os imprimir, e de outra parte, a criação de mapas próprios como mapas diacrônicos da ocupação do solo a partir de camadas de informação disponíveis em diferentes datas. Por exemplo, a diminuição da superfície de "Vergers hautes tiges" , espécie rústica, a favor da urbanização (figura 18). Para os usuários que dispõem de ferramentas de tratamento de dados geográficos localizados, é possível adicionar camadas de informação em diferentes formatos (DABERT, SERRADJ e HIRLEMANN, 2010). 


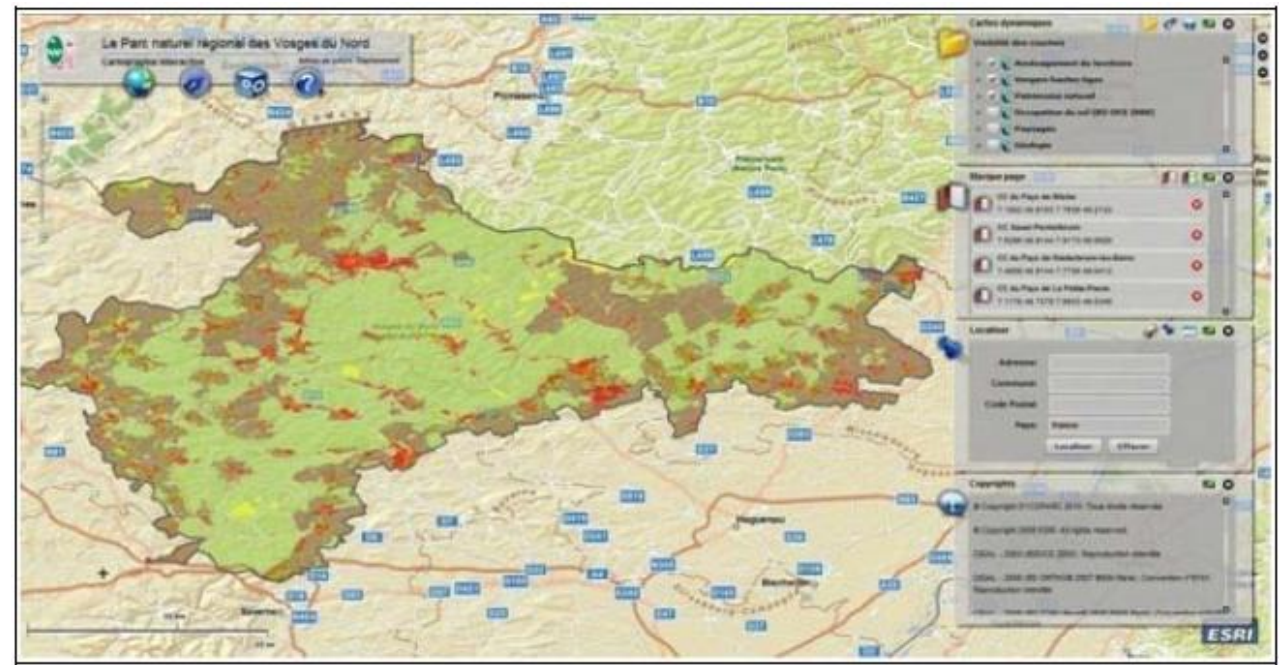

Figura 17: Página inicial e Interface da cartografia interativa do Pnr-Vosges do Norte.

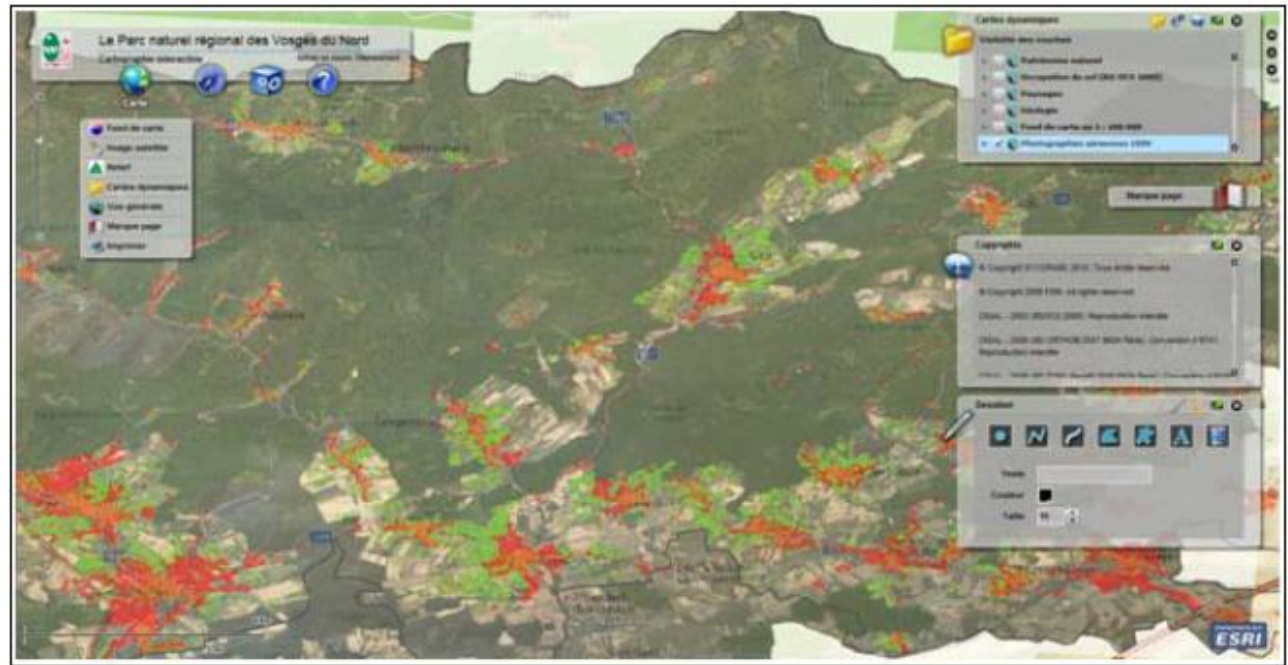

Figura 18: Resultado de uma requisição em cartografia interativa do Pnr-Vosges do Norte.

Uma das perspectivas, a curto prazo, da cartografia interativa desenvolvida e posta em prática sobre o servidor do Parque Natural de Vosges do Norte é torná-lo operacional com uma interface de carregamento de dados publicados sob a forma de serviços, pondo à disposição os dados do Syroparc em outras plataformas.

\section{A aplicação CartoFire}

Um exemplo de servidor de mapas é o serviço CartoFire do Departamento de Geografia da Universidade de Alcalá (Espanha) (Figura 19). O servidor de Alcalá corresponde ao projeto multidisciplinar FireMap, agrupando os pesquisadores-engenheiros de diferentes domínios: ecologia, economia e geografia (ALLOZA, BAEZA, DE LA RIVA et al., 2006). O objetivo 
principal é desenvolver um conjunto de métodos para construir sob forma cartográfica um índice sintético dos riscos de incêndio de florestas. A plataforma criada a este fim - CartoFire - possui uma dupla função:

$\checkmark$ adaptar ao projeto FireMap uma ferramenta de gestão cartográfica à distância que permite a análise, em tempo real, do comportamento das variáveis de risco ao início de incêndios na floresta;

$\checkmark$ permitir ao conjunto de pesquisadores implicados de compartilhar seus dados cartográficos e acessar às informações de cada grupo, qual seja sua localização na Espanha.

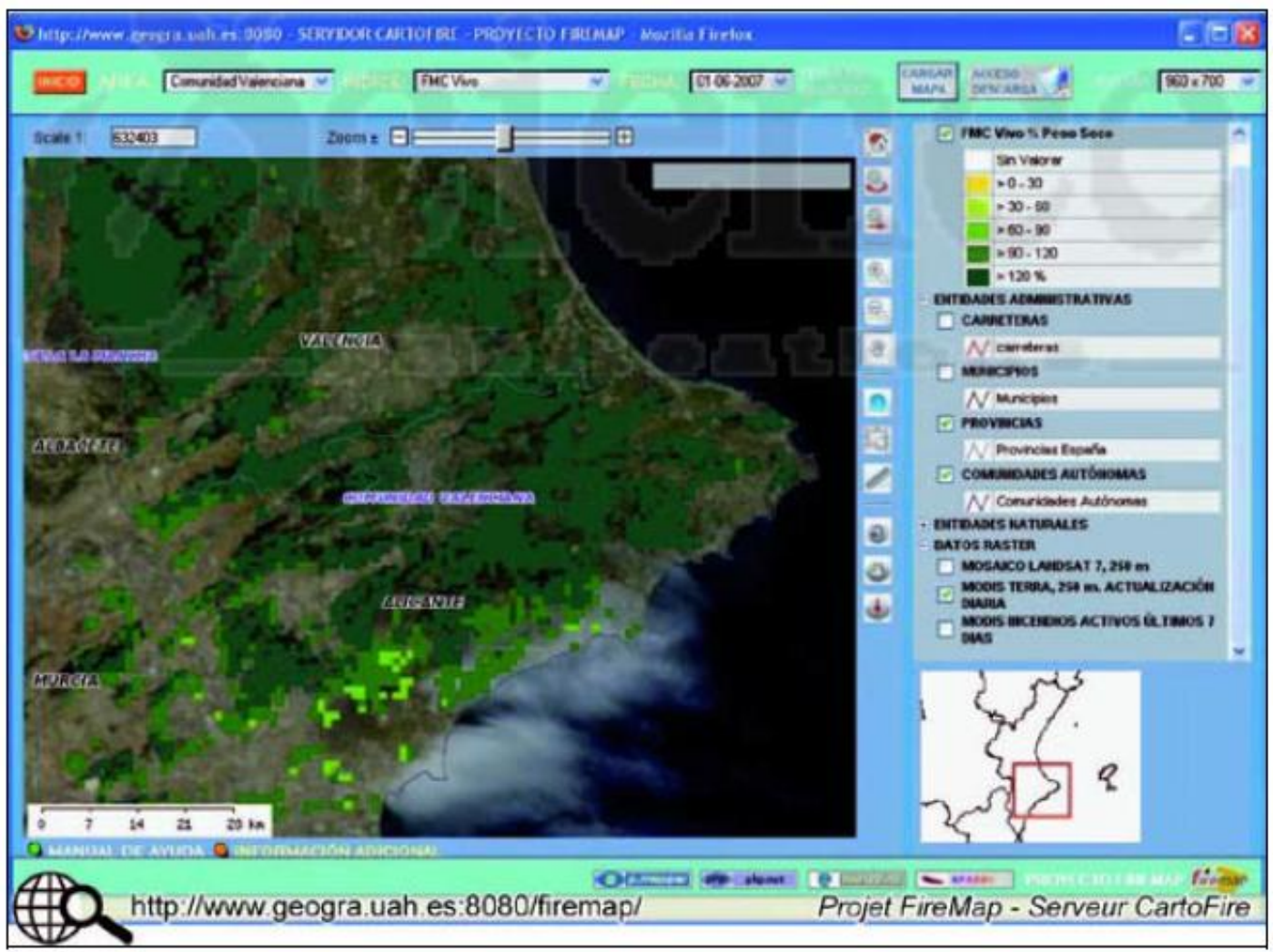

Figura 19. Página inicial do website da aplicação (CAUVIN, ESCOBAR e SERRADJ, 2008b).

A aplicação CartoFire (figura 19) se apóia em um servidor cartográfico online, fundindo-se à tecnologia Web Mapping e utilizando um código livre (Open Source) como fonte para a programação (PADRON e ESCOBAR, 2006). O servidor tem como base um sistema de informações com digitalização, estocagem de dados e aplicativos.

A paisagem informática é alterada continuamente pela utilização dos servidores que se multiplicam e pelas linguagens que se aperfeiçoam regularmente. Ao mesmo tempo, uma das transformações mais importantes nesses últimos anos é sem dúvida o aparecimento dos 
programas livres que permitem continuar o desenvolvimento da universidade e onipresença da cartografia.

\section{CONCLUSÃO}

Nesta comunicação, escolhemos privilegiar certas tecnologias em relação a outras. Seria impossível cobrir o conjunto de possibilidades atuais, sobretudo porque as mudanças estão constantemente em curso. Novas transformações, novos procedimentos aparecem sem cessar, portanto é necessário testar a validade para melhorias e enriquecimento da informação geográfica e sua expressão pela cartografia, além do interesse por aplicativos concretos, como os Location Based Services (LBS) desenvolvidos, entre outros, pela sociedade GeoConcept.

\section{BIBLIOGRAFIA}

ALLOZA J. A., BAEZA M. J., DE LA RIVA J., et al., 2006, A model to evaluate the ecological vulnerability to forest fires in Mediterranean ecosystems, $V$ International Conference on Forest Fire Research, Figueira da Fos, 20-27 p.

BAGOT J. D., 1999, Information, sensation et perceptions, Armand Colin, Paris, 266 p.

BALESTRA M., CHERY, J.P., VALETTE, E., BARBE, E., 2008, Suivi des changements d'occupation et d'utilisation du sol pour la compréhension des dynamiques périurbaines: étude méthodologique pour le suivi des terres agricoles affectées par l'artificialisation, Colloque de I'ASRDLF : Territoire et action publique territoriale : nouvelles ressources pour le développement régional, Québec, Canada,

BARREDO J. I., KASANKO M., McCORMICK N., et al., 2003, Modelling dynamic spatial processes: simulation of urban future scenarios through cellular automata, Landscape and Urban Planning, pp. 145-160.

BARREDO J. I., LAVALLE C., KASANKO M., et al., 2003, The MOLAND activities on urban scenario modelling and forecast, Luxembourg, Office for Official Publications of the European Communities, $54 \mathrm{p}$. 
BLOK C., 1998, Dynamic visualization variables in a developing framework for the representation of geographic data, Bulletin du Comité Français de Cartographie, $n^{\circ} 156, p p$. 89-97.

CAUVIN C., ESCOBAR F., SERRADJ A., 2008a, Cartographie thématique 4 : Des transformations renouvelées, Lavoisier - Hermes Science, Paris, 198 p.

CAUVIN C., ESCOBAR F., SERRADJ A., 2008b, Cartographie thématique 5 : Des voies nouvelles à explorer, Lavoisier - Hermes Science, Paris, 320 p.

CAUVIN C., REYMANN I., 2004, Des usages de l'image dans une publication., L'information géographique, $n^{\circ} 2$, pp. 1-17

CHION M., 1994, Audi-vision, sound and screen, Columbia University press New York, 240p.

COLL E., MARTINEZ J. C., SANZ J. G., et al., 2005, Introduccion a la publicacion de cartografia en Internet, Valencia, Geodesia y Fotogrametria, 167 p.

COOLEY M., 1998, Sound + image in computer-based design: learning from sound in the arts, ICAD'98 5th International Conference on Auditory Display, British Computer Society, Glasgow, UK, $10 \mathrm{p}$.

CURIE F., MAS A., PERRET J., et al., 2010, Simuler la densification du tissu urbain au moyen de processus de peuplement, SAGEO 2010, Toulouse, 15 Pages.

DABERT K., SERRADJ A., HIRLEMANN G., 2010, Utilisation des technologies de l'information et de la communication pour diffuser l'information géographique de l'Observatoire du Parc naturel régional des Vosges du Nord, Géomatique Expert, vol. 77, nº, pp. 21.

DENÈGRE J., SALGÉ F., 2004, Les sytèmes d'information géographique., PUF, Que sais-je ? Nº 3122,128 p.

DENEGRE J. s. I. d., 2005, Sémiologie et conception cartographique., Hermès Science Lavoisier Collection ENSG - IGN, 275 p.

ENGELEN G., WHITE R., ULEE I., et al., 2004, The MOLAND model for Urban and Regional growth, Maastricht, $112 \mathrm{p}$ 
FERBER J., 1995, Les Systèmes multi-agents: Vers une intelligence collective, InterEditions, Paris, $522 \mathrm{p}$.

FOLEY D. J., al, 1995, Introduction à l'infographie, Addison-Wesley France, Paris, New York, $573 \mathrm{p}$.

GIL QUIJANO J., 2007, Modèles d'auto-organisation pour l'émergence de formes urbaines à partir de comportements individuels à Bogota, Spécialité Informatique, Paris 6, Paris, 294 p.

KRUSKAL W. H., YOUNG F. W., SEERY J. B., 1977, How to use KYST 2, a very flexible program to do multidimensional scaling and unfolding, pp. 72 p.

KRYGIER J. B., 1994, Sound and geographic visualisation, In Visualisation in Modern Cartography, Taylor, editor, New York, pp. 149-165.

KRYGIER J. B., 1996, Geography and cartographic design, In Cartographic design: theoritical and practical perspectives, J. W. a. sons, editor, New York, pp. 19-34.

MULLER J.-C., SCHARLACH H., 2001, Maps and Sounds, Bochum, Ruhr-University of Bochum, Section of geomatics.

PADRON D., ESCOBAR F., 2006, Servidores Webmapping y Catálogos de Metadatos : una experiencia para el establecimiento de una cooperativa de datos espaciales, Geo-Focus, vol. 7,

PETERSON M. P., editor, 2005, Maps and the Internet, Oxford (G.B.), Elsevier - ICA, 450 p.

REYMANN I., CAUVIN C., 1996, Le rail et la route en France. Accessibilité comparée 19932015., In DATAR, editor, 160 p.

RONCARELLI R., 1989, Computer Animation Dictionary, Spinger-Verlag, New-York, 124 p.

SANDERS L., 2006, Les modèles agent en géographie urbaine, In Modélisation et simulation multi-agents ; applications pour les Sciences de I'Homme et de la Société, F. AMBLARD, D. PHAN, editors, Paris: Hermes Science Publications, Lavoisier, pp. 151-168.

TOBLER W. R., 1977, Bidimensional regression: a computer program, 71 p. ronéo p. 
TOMLINSON R. F., 1988, The impact of the transition from analogue to digital cartographic representation, The American Cartographer, vol. 15, n 3, pp. 249-262. 